\title{
53BP1 foci as a marker of tumor cell radiosensitivity
}

\author{
E. MARKOVA ${ }^{1}$, S. VASILYEV $V^{1,2}$, I. BELYAEV $V^{1, *}$ \\ ${ }^{1}$ Laboratory of Radiobiology, Cancer Research Institute, Slovak Academy of Sciences, Bratislava, Slovakia; ${ }^{2}$ Laboratory of Cytogenetics, Institute \\ of Medical Genetics, Tomsk, Russia \\ ${ }^{*}$ Correspondence: Igor.Beliaev@savba.sk
}

Received May 7, 2015 / Accepted July 9, 2015

\begin{abstract}
Predicting tumor radiosensitivity has yet to be routinely integrated into radiotherapy. We analyzed the possibility to assess radiosensitivity of tumor cells based on endogenous and radiation-induced 53BP1 foci which are molecular markers of DNA double strand breaks (DSB). In eleven tumor cell lines of different origin, radiosensitivity was assessed by surviving cell fraction following irradiation with $2 \mathrm{~Gy}$ (SF2). 53BP1 foci were measured at 4 and $12 \mathrm{~h}$ post-irradiation by confocal laser microscopy and dedicated software. The correlation of 53BP1 foci and their post-irradiation kinetics with SF2 was assessed using Spearman rank test. The SF2 correlated with both excess of radiation-induced 53BP1 foci per cell at $4 \mathrm{~h}$ after irradiation and decay in number of 53BP1 foci from 4 to $12 \mathrm{~h}$ post-irradiation. The fraction of cells with multiple endogenous 53BP1 foci also correlated with SF2 of tumor cells. We conclude that the radiosensitivity of tumor cells can be predicted by kinetics of formation and decay of 53BP1 foci after irradiation. For the first time we report that the fraction of cells with multiple endogenous 53BP1 foci can be used as a marker of tumor cell radiosensitivity.
\end{abstract}

Key words: 53BP1, DNA double strand breaks, tumor cells, clonogenic survival, radiosensitivity

Radiosensitivity is highly variable between human tumor cells. DNA double strand breaks (DSB) are the most detrimental type of molecular damage causing cell death if not repaired. The cytological manifestation of DSB is a formation of so-called DNA repair foci aimed to both DNA repair and activation of cell cycle checkpoints. These foci can be visualized by fluorescent/confocal microscopy. The most useful markers of DNA repair foci are phosphorylated histone 2A family member $\mathrm{X}(\gamma \mathrm{H} 2 \mathrm{AX})$ and tumor suppressor $\mathrm{p} 53$ binding protein 1 (53BP1) that may represent a predictive tool for radiation oncology [1]. In general, there is no correlation between primary DSB and cellular radiosensitivity [2]. However, residual 53BP1 and $\gamma-\mathrm{H} 2 \mathrm{AX}$ foci, which persist relatively long time after irradiation, and the rate of DNA repair focus decay may correlate with cellular radiosensitivity [3-9]. Normal and tumor human cells have variable level of endogenous $\gamma \mathrm{H} 2 \mathrm{AX}$ and 53BP1 foci with still elusive nature. Endogenous $\gamma \mathrm{H} 2 \mathrm{AX}$ can mark unrepaired or misrepaired DSB induced by oxidative stress and other cellular factors [10]. Also, these foci may remain at the sites of chromatin with changed conformation $[11,12]$ or mark the eroded telomeres $[13,14]$. The localization of endogenous $\gamma \mathrm{H} 2 \mathrm{AX}$ and 53BP1 foci on the eroded telomeres in tumor cells can be a marker of chromosome instability and correspond to higher radiosensitivity [15]. The presence of active $\gamma \mathrm{H} 2 \mathrm{AX}$ and 53BP1 foci may lead to apoptosis [16], cell senescence [17] and cell cycle checkpoint activation [13] impairing proliferative capacity of tumor cells.

Due to different kinetics of formation and decay, $\gamma \mathrm{H} 2 \mathrm{AX}$ and 53BP1 foci do not always co-localize [2]. Thus, the potential of DNA repair foci for assessment of radiosensitivity may vary depending on molecular marker and time of observation. It was reported that kinetics of radiation-induced $\gamma \mathrm{H} 2 \mathrm{AX}$ foci after irradiation correlated with clonogenic survival of normal human fibroblasts [18] and cancer cell lines [19]. However, other studies did not confirm such correlation $[20,21]$. Kinetics of $\gamma \mathrm{H} 2 \mathrm{AX} / 53 \mathrm{BP} 1$ foci correlated with cell survival in human lymphoblastoid cells lines with impaired DNA damage response (DDR) [22]. Relationship between $53 \mathrm{BP} 1$ foci and radiosensitivity of tumor cells remains to be elucidated. In this study, we analyzed the relationship between the level of endogenous 53BP1 foci, kinetics of radiationinduced 53BP1 foci and SF2 using eleven tumor cell lines of different origin. 


\section{Materials and methods}

Chemicals. Reagent grade chemicals were obtained from Sigma (St. Louis, MI, USA) and Merck KgaA (Darmstadt, Germany).

Cells. We used human tumor cells Saos-2 and Saos-2His-273 (osteosarcoma); H1299tTA and H1299tTA-His175 (lung adenocarcinoma), all a gift from Prof. G. Selivanova (Karolinska Institutet, Stockholm, Sweden); bladder cancer cell lines RT112, HT1376, UM-UC-3, T24, J82, all a gift from Prof. S. McKeown, University of Ulster, Coleraine, UK; ovarian cancer cell lines SK-OV-3 and A2780, a gift from Dr. J. Sedlak, Cancer Research Institute, Bratislava, Slovakia; and normal human fibroblasts VH-10, a gift from Dr. A. Kolman, Stockholm University, Sweden. The cells were maintained in monolayer with twice weekly subculture in $260 \mathrm{ml}$ Nunclon flasks (Nunc, Denmark) in 1:1 Dulbecco's Modified Eagle Medium without pyruvate, and Nutrient Mixture Ham's F10 medium with glutamine (Gibco, BRL) supplemented with $10 \%$ fetal bovine serum, $50 \mathrm{U} / \mathrm{ml}$ penicillin, and $50 \mu \mathrm{g} / \mathrm{ml}$ streptomycin (Gibco, $\mathrm{BRL}$ ) in an humidified CO2 incubator at $37 \mathrm{oC}$. Cell numbers were counted during cultivation and the doubling time was calculated based on cell numbers.

Irradiation. As soon as exponentially growing cells reached monolayer, they were placed on ice for $30 \mathrm{~min}$ and then irradiated with $2 \mathrm{~Gy}$ of $60 \mathrm{Co} \gamma$-rays at a dose rate of $0.64 \mathrm{~Gy} / \mathrm{min}$ using an CHISOBALT B72 source (Chirana, Praha, Czech Republic).

Clonogenic survival. Cell radiosensitivity was assessed by the surviving fraction following irradiation with $2 \mathrm{~Gy}$ in vitro (SF2) using a soft agar clonogenic assay [23]. Plating efficiency (PE) and SF2 was determined in three independent experiments for each cell line.

53BP1 focus analysis. Our preliminary data suggested that the post-irradiation time used for estimation of radiosensitivity at therapeutically relevant doses in proliferating cells by scoring residual foci should be limited by the duration of the cell cycle [23]. Therefore, we analyzed 53BP1 foci at $4 \mathrm{~h}$ and $12 \mathrm{~h}$ post-irradiation. The immunostaining was performed as we described previously [23]. Images were acquired from randomly selected fields using a confocal laser scanning microscope (Zeiss Axiovert 100M, Carl Zeiss Microscopy, Jena, Germany). The Z-stacks of ten images were acquired from optical sections $1 \mu \mathrm{m}$ apart and section thickness of $2 \mu \mathrm{m}$. Resolutions in the X-and Y-axis was $0.2 \mu \mathrm{m}$. The final image was obtained by maximum intensity projection of all sections onto one plane. The foci were counted on these final images by using the Metafer 4.0 software (Metasystems, Germany). For each data point, 300-600 cells were analyzed from 5-10 randomly selected fields of vision from two slides per treatment condition. All procedures were run automatically and the same intensity threshold was used within each experiment. Numbers of foci obtained by software analysis highly correlated with foci counted in blind by eye.

Statistical analysis. The levels of 53BP1 foci in irradiated and sham-irradiated cells were compared by Wilcoxon matched pairs test. Spearman rank test was used for correlation analysis. All statistical procedures were performed using Statistica 8.0 (Statsoft, USA).

\section{Results}

Highly significant positive correlation between PE and SF2 was found (Fig.1). This correlation could reflect the common mechanisms underlining colony-forming capacity of tumor cells under endogenous and radiation-induced stress. Doubling time was longer in cell lines with lower colony-forming capacity in unirradiated cells (Fig. 2). In clonogenic survival

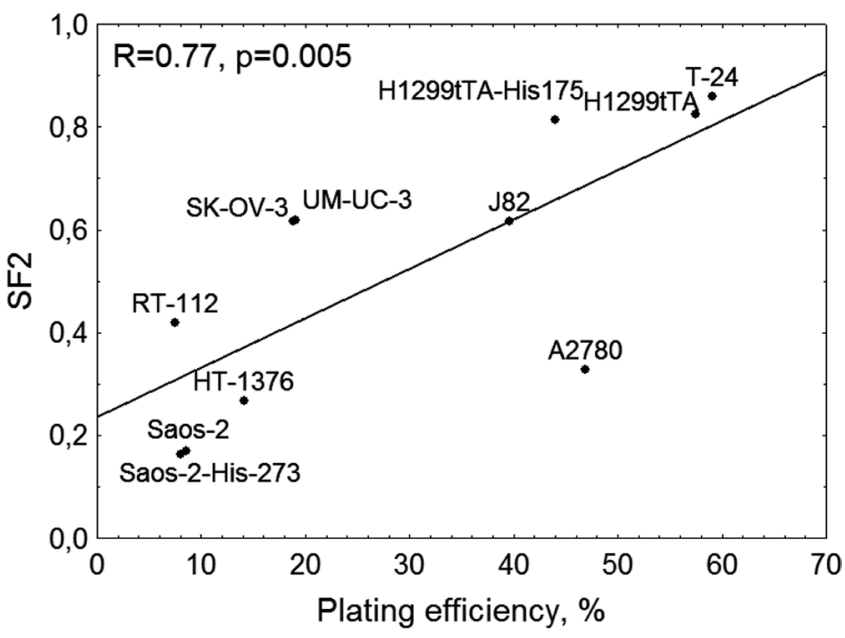

Figure 1. Relationship of plating efficiency (PE) and radiosensitivity. Correlation between PE and clonogenic cell survival (SF2) is shown. Linear regression is indicated as solid line along with the Spearman's rank correlation coefficient $(R)$ and p-value. Each data point represents mean value from three independent experiments in this and other figures.

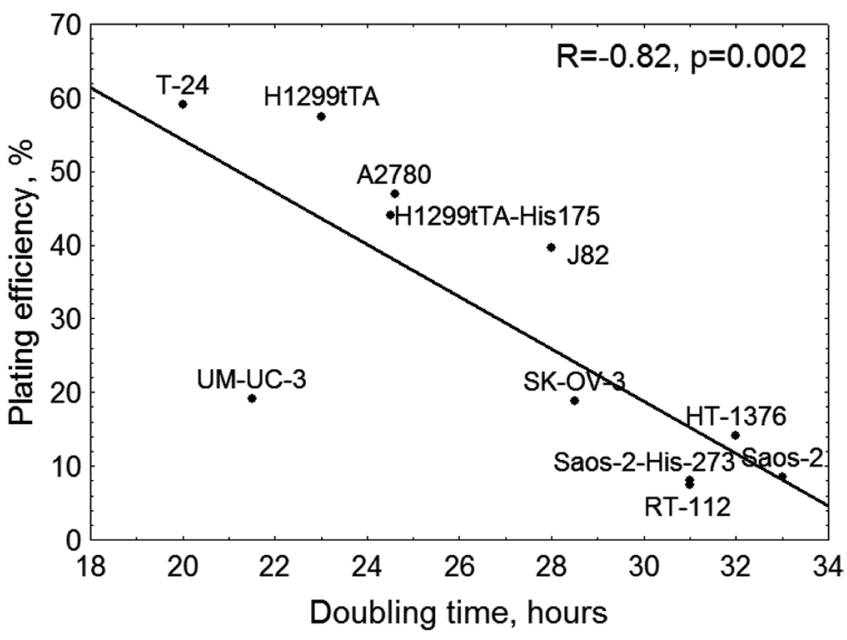

Figure 2. Correlation of PE with doubling time. Doubling time was longer in cell lines with lower colony-forming capacity. Linear regression is indicated as solid line along with the Spearman's rank correlation coefficient (R) and p-value. 

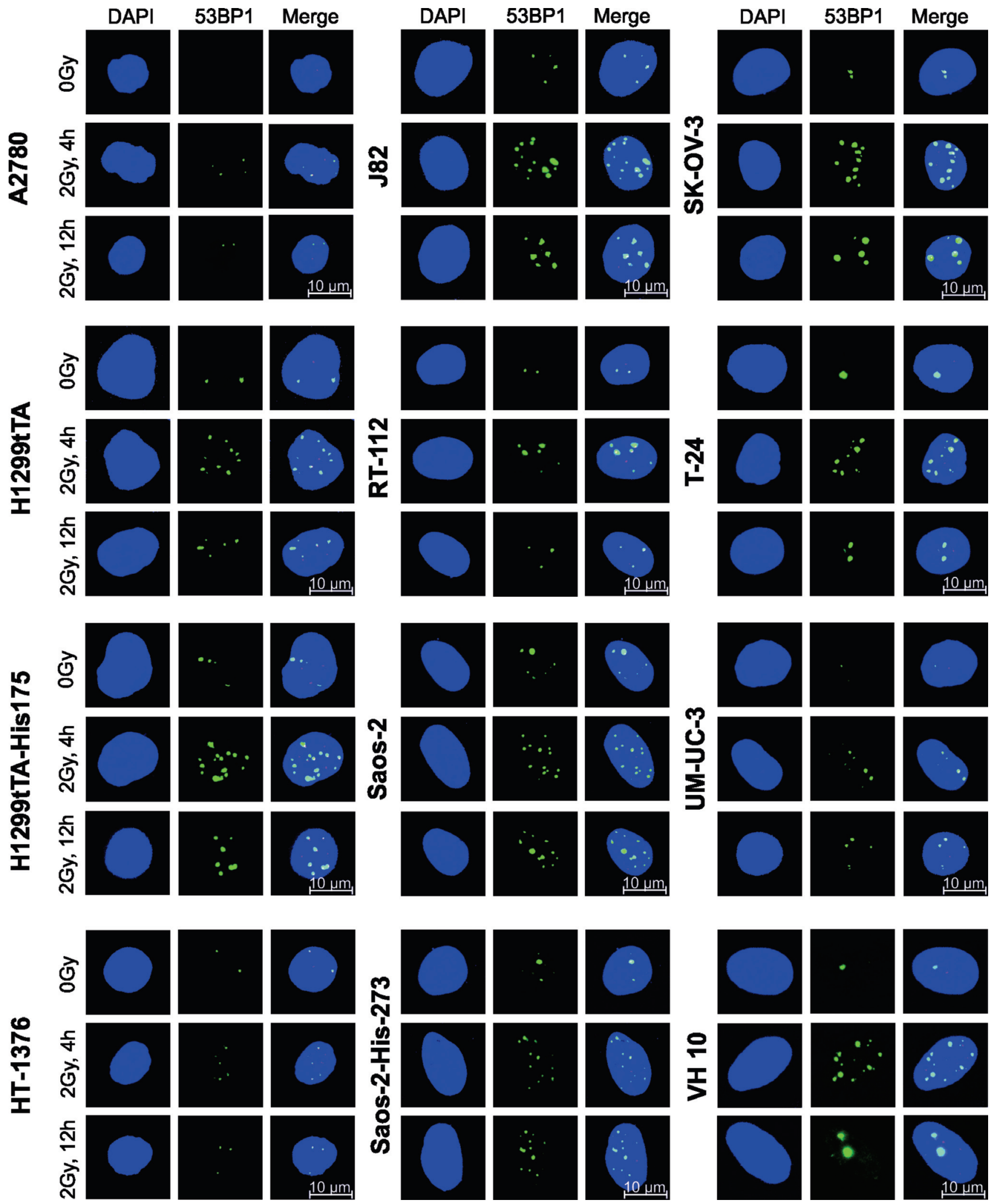

Figure 3. Representative images of 53BP1 foci in tumor cells. Cells were irradiated with 2 Gy or sham irradiated (0 Gy) and fixed 4 or 12 hours postirradiation for enumeration of 53BP1 foci by confocal laser microscopy. DNA was stained by DAPI in blue (first column) and 53BP1 foci were stained using appropriate antibodies in green (second column). Merged images from two channels (green, blue) are shown in the third column. 


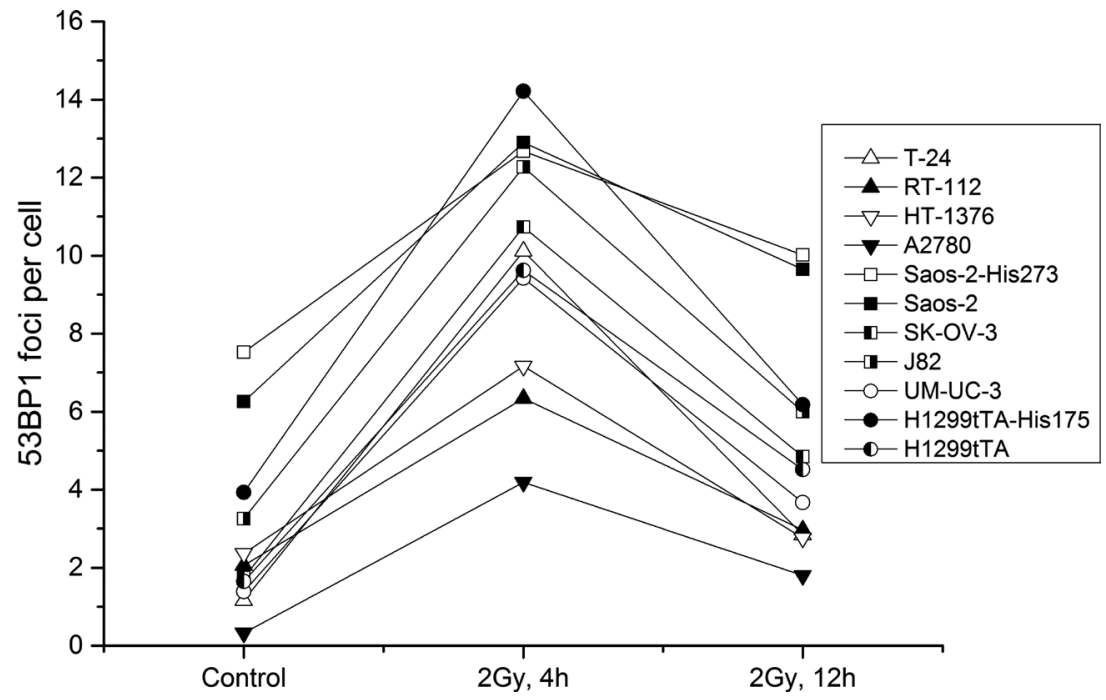

Figure 4. Kinetics of 53BP1 foci in tumor cells. Levels of 53BP1 foci in tumor cell lines at 4 and $12 \mathrm{~h}$ after irradiation to $2 \mathrm{~Gy}$ and in sham-irradiated control are shown.

assay, the colonies were counted two weeks after plating the cells when appearance of colonies of different cell types is usually saturated. Thus, the lower plating efficiency of cells with larger doubling time was unlikely caused by the undercount of colonies due to not sufficient time allowed to grow. Such correlation indicates slower cell cycle, higher cell death rate or lower number of divided cells in cell lines with lower colonyforming capacity. Considering that the PE negatively correlated with the doubling time (Fig. 2), it might be expected that SF2 would also negatively correlate with the doubling time. Indeed, statistically significant correlation was observed between SF2 and doubling time $(\mathrm{R}=-0.87, \mathrm{p}=0.0004)$

All cell lines responded to ionizing radiation by formation of 53BP1 foci which noticeably exceeded the number of endogenous foci in sham-irradiated cells (Fig. 3). There were no differences in the level of endogenous foci measured $4 \mathrm{~h}$ and $12 \mathrm{~h}$ after sham-irradiation. Therefore, averaged values from $4 \mathrm{~h}$ and $12 \mathrm{~h}$ are shown in Fig. 4. All tumor cell lines except for A2780 had more endogenous 53BP1 foci than normal human fibroblasts VH10 ( $<$ 0.05). These data are in line with previous observations on increased level of endogenous DNA repair foci in tumor cells [15].

Endogenous level of 53BP1 foci correlated negatively with PE (Fig. 5). Positive correlation of endogenous 53BP1 foci with doubling time, which might be expected from correlations shown in Figure 2 and Figure 5 was statistically significant $(R=$ $0.66, p=0.027)$. The endogenous foci can reflect both the level of background DSB and efficiency of DDR. Thus, the cell lines with decreased PE and increased doubling time either have more background DSB or possess a better signaling network with active checkpoints resulting in cell cycle arrest. In line with our data, Yu et al. reported almost the same correlation between $\gamma \mathrm{H} 2 \mathrm{AX}$ foci and doubling time [15]. Altogether these data indicate a close relationship between endogenous DNA repair foci and proliferative capacity of tumor cells.

Negative correlation between the number of endogenous 53BP1 foci and SF2 did not reach a statistical significance $(\mathrm{R}=$ $-0.45, p=0.16)$. In each cell line, a significant fraction of cells contained more then one endogenous 53BP1 focus (Fig. 6). Moreover, a fraction of cells with multiple endogenous foci up to $15 \mathrm{foci} /$ cells were seen in tumor cells in accordance with previous reports [15]. If these cells would have a stronger signaling network with active checkpoints resulting in cell cycle arrest and cell senescence or impaired DDR they may be more sensitive to endogenous and radiation-induced stress

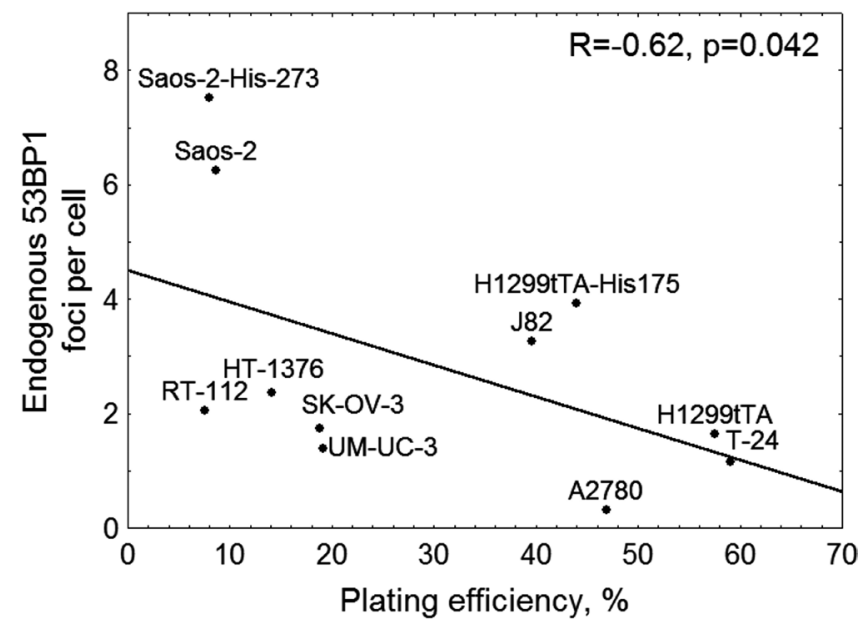

Figure 5. Correlation between endogenous 53BP1 foci and PE. Endogenous 53BP1 foci correlated negatively with PE. Linear regression is indicated as solid line along with the Spearman's rank correlation coefficient $(R)$ and p-value. 


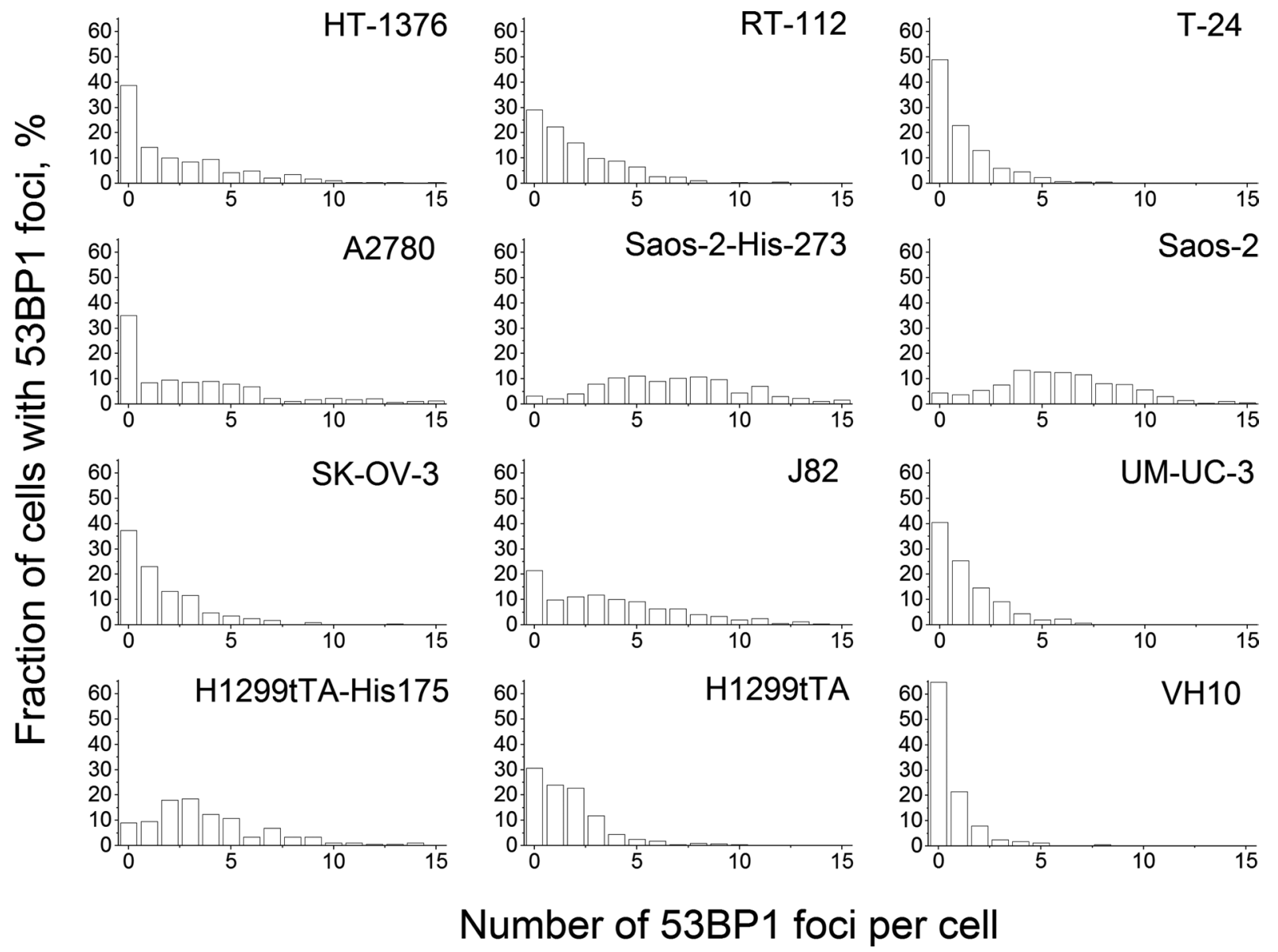

Figure 6. Level of endogenous 53BP1 foci in cell lines. Fractions of cells with various numbers of endogenous 53BP1 foci are shown.

as measured with PE and SF2, respectively. To validate this hypothesis, we analyzed whether the correlation between the number of endogenous 53BP1 and SF2 is affected by a fraction

Table 1. Correlations of PE, doubling time and SF2 of tumor cell lines with fraction of cells harboring various numbers of endogenous 53BP1 foci. The values shown in Fig. 6 were included in the correlation analysis.

\begin{tabular}{|c|c|c|c|c|c|c|}
\hline \multirow{2}{*}{$\begin{array}{l}\text { Number } \\
\text { of foci } \\
\text { per cell }\end{array}$} & \multicolumn{2}{|c|}{$\mathrm{PE}$} & \multicolumn{2}{|c|}{ Doubling time } & \multicolumn{2}{|c|}{ SF2 } \\
\hline & $\mathrm{R}$ & p-value & $\mathrm{R}$ & $\mathrm{p}$-value & $\mathrm{R}$ & p-value \\
\hline$\geq 1$ & -0.509 & 0.110 & 0.515 & 0.105 & -0.536 & 0.089 \\
\hline$\geq 2$ & -0.509 & 0.110 & 0.647 & 0.031 & -0.718 & 0.013 \\
\hline$\geq 3$ & -0.445 & 0.170 & 0.638 & 0.035 & -0.718 & 0.013 \\
\hline$\geq 4$ & -0.445 & 0.170 & 0.638 & 0.035 & -0.718 & 0.013 \\
\hline$\geq 5$ & -0.445 & 0.170 & 0.638 & 0.035 & -0.718 & 0.013 \\
\hline$\geq 6$ & -0.482 & 0.133 & 0.629 & 0.038 & -0.736 & 0.010 \\
\hline$\geq 7$ & -0.445 & 0.170 & 0.638 & 0.035 & -0.718 & 0.013 \\
\hline$\geq 8$ & -0.355 & 0.285 & 0.624 & 0.040 & -0.727 & 0.011 \\
\hline$\geq 9$ & -0.318 & 0.340 & 0.583 & 0.060 & -0.709 & 0.015 \\
\hline$\geq 10$ & -0.382 & 0.247 & 0.597 & 0.053 & -0.736 & 0.010 \\
\hline$\geq 11$ & -0.327 & 0.326 & 0.542 & 0.085 & -0.718 & 0.013 \\
\hline
\end{tabular}

of cells containing multiple 53BP1 foci. This correlation was statistically significant for the fractions of cells with two and more endogenous 53BP1 foci (Table 1). We concluded that the fraction of cells with multiple endogenous 53BP1 foci may be used as a marker of tumor cell radiosensitivity.

The increase in fraction of cells with one and more foci consistently correlated with decrease in doubling time ( $\mathrm{Ta}$ ble 1). These data further indicate possible impact of 53BP1 endogenous foci on the checkpoint signaling network in tumor cells.

SF2 correlated with both excess of radiation-induced 53BP1 foci at $4 \mathrm{~h}$ after irradiation and decay of number of 53BP1 foci from 4 to $12 \mathrm{~h}$ after irradiation (Fig. 7). Therefore, tumor cells with faster removing 53BP1 foci (i.e. faster DSB repair) are more resistant to ionizing radiation.

\section{Discussion}

$53 \mathrm{BP} 1$ is a mediator that relays signals from DNA damage sensors and activates various effectors facilitating DNA repair, cell cycle arrest and cell survival. In this study, we investigated $53 \mathrm{BP} 1$ foci as a predictor for radiosensitivity of tumor cells. 

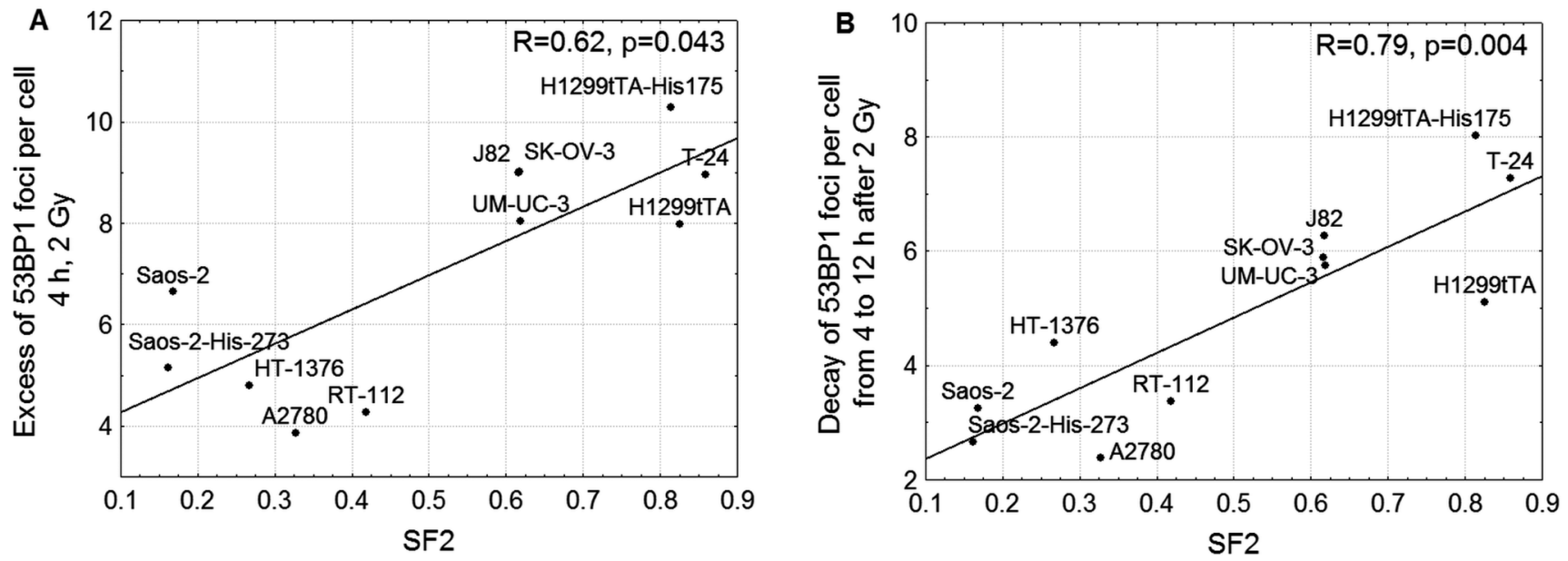

Figure 7. Correlation between radiosensitivity and kinetics of radiation-induced 53BP1 foci. SF2 positively correlated with: (A) excess of radiationinduced 53BP1 foci at $4 \mathrm{~h}$ after irradiation over the control level; (B) decay in number of 53BP1 foci from 4 to $12 \mathrm{~h}$ post-irradiation. Linear regression is indicated as solid line along with the Spearman's rank correlation coefficient $(R)$ and $p$-value.

We found that cancer cell lines with lower rates of both formation and decay of radiation-induced 53BP1 foci had decreased SF2. It is likely to be a result of impaired DDR and checkpoint signaling network in radiosensitive cell lines.

For the first time, we have shown that the larger fraction of cells with multiple endogenous 53BP1 foci is associated with both slower progression of cell cycle and lower SF2. Cell lines with high numbers of endogenous 53BP1 might be less capable to repair radiation-induced DNA damage and therefore would be more radiosensitive. Endogenous 53BP1 foci may mark the eroded telomeres or clustered unrepaired DSB [14] which frequently lead to chromosome instability in cancer cells [24]. Therefore, cells with multiple endogenous 53BP1 foci may represent subpopulations of tumor cells with higher level of chromosome instability. In its turn, chromosome instability results in delayed cell cycle and lower PE of cell lines. A new finding of this study on negative correlation between the cell fractions with multiple endogenous foci and SF2 may provide a cost-effective and time saving alternative to more complex techniques which include irradiation in vitro.

We have found statistically significant correlation between the number of endogenous 53BP1 foci and $\mathrm{PE} /$ doubling time. On the other hand, there were no correlation between plating efficiency and endogenous $\gamma \mathrm{H} 2 \mathrm{AX}$ foci in six normal and tumor cells lines [20]. It should be noted that due to significantly different kinetics of decay, endogenous 53BP1 and $\gamma \mathrm{H} 2 \mathrm{AX}$ foci have a low level of co-localization in both normal and tumor human cells [2]. The difference in kinetics of decay may underlie a better correlation of 53BP1 with PE and doubling time. The doubling time is closely related with the regulation of cell cycle. Our data on correlation of PE and SF2 with doubling time warrants further studies aiming to validate whether cell populations in G1 - , S - , or G2 - phase would correlate with radiosensitivity.
Acknowledgements: The authors are thankful to Mrs. Petra Petrovicova and Mr. Lucian Zastko for excellent technical assistance and Ing. Ernest Mrštak, Military Hospital, Ružomberok, Slovak Republic, for irradiation of samples. This study was supported by the Structural Funds of EU (Agency) by the Ministry of Education, Science, Research and Sport of the Slovak Republic (Protonbeam, ITMS: 26220220129), the Grant Agency VEGA (2/0178/11) of the Slovak Republic, the Joint Research Project "Individual radiosensitivity of cancer patients" between Slovak Academy of Sciences (SAS) and Russian Academy of Medical Sciences (RAMS).

\section{References}

[1] POULILIOU S, KOUKOURAKIS MI Gamma histone 2AX (gamma-H2AX)as a predictive tool in radiation oncology. Biomarkers 2014; 19: 167-180. http://dx.doi.org/10.3109/13 54750X.2014.898099

[2] BELYAEV IY Radiation-induced DNA repair foci: spatiotemporal aspects of formation, application for assessment of radiosensitivity and biological dosimetry. Mutat Res 2010; 704: 132-141. http://dx.doi.org/10.1016/i.mrrev.2010.01.011

[3] MACPHAIL SH, BANATH JP, YU TY, CHU EH, LAMBUR $\mathrm{H}$ et al. Expression of phosphorylated histone H2AX in cultured cell lines following exposure to X-rays. International Journal of Radiation Biology 2003; 79: 351-358. http://dx.doi. org/10.1080/0955300032000093128

[4] KUHNE M, RIBALLO E, RIEF N, ROTHKAMM K, JEGGO PA et al. A double-strand break repair defect in ATM-deficient cells contributes to radiosensitivity. Cancer Research 2004; 64: 500-508. http://dx.doi.org/10.1158/0008-5472.CAN-03$\underline{2384}$

[5] OLIVE PL, BANATH JP Phosphorylation of histone H2AX as a measure of radiosensitivity. International Journal of Radiation Oncology Biology Physics 2004; 58: 331-335. http:// dx.doi.org/10.1016/j.ijrobp.2003.09.028 
[6] TANEJA N, DAVIS M, CHOY JS, BECKETT MA, SINGH R et al. Histone H2AX phosphorylation as a predictor of radiosensitivity and target for radiotherapy. Journal of Biological Chemistry 2004; 279: 2273-2280. http://dx.doi.org/10.1074/ jbc.M310030200

[7] WYKES SM, PIASENTIN E, JOINER MC, WILSON GD, MARPLES B Low-dose hyper-radiosensitivity is not caused by a failure to recognize DNA double-strand breaks. Radiat Res 2006; 165: 516-524. http://dx.doi.org/10.1667/ $\underline{\text { RR3553.1 }}$

[8] IWABUCHI K, BASU BP, KYSELA B, KURIHARA T, SHIBATA $M$ et al. Potential role for 53BP1 in DNA end-joining repair through direct interaction with DNA. J Biol Chem 2003; 278: 36487-36495. http://dx.doi.org/10.1074/jbc. M304066200

[9] ROTHKAMM K, LOBRICH M Evidence for a lack of DNA double-strand break repair in human cells exposed to very low x-ray doses. Proc Natl Acad Sci U S A 2003; 100: 5057-5062. http://dx.doi.org/10.1073/pnas.0830918100

[10] SEDELNIKOVA OA, HORIKAWA I, ZIMONJIC DB, POPESCU NC, BONNER WM et al. Senescing human cells and ageing mice accumulate DNA lesions with unrepairable double-strand breaks. Nat Cell Biol 2004; 6: 168-170. http:// dx.doi.org/10.1038/ncb1095

[11] HAN J, HENDZEL MJ, ALLALUNIS-TURNER J Quantitative analysis reveals asynchronous and more than DSB-associated histone H2AX phosphorylation after exposure to ionizing radiation. Radiat Res 2006; 165: 283-292. http://dx.doi. org/10.1667/RR3516.1

[12] KATO TA, OKAYASU R, BEDFORD JS Comparison of the induction and disappearance of DNA double strand breaks and gamma-H2AX foci after irradiation of chromosomes in G1-phase or in condensed metaphase cells. Mutat Res 2008; 639: 108-112. http://dx.doi.org/10.1016/j. mrfmmm.2007.11.006

[13] FUMAGALLI M, ROSSIELLO F, CLERICI M, BAROZZI S, CITTARO D et al. Telomeric DNA damage is irreparable and causes persistent DNA-damage-response activation. Nat Cell Biol 2012; 14: 355-365. http://dx.doi.org/10.1038/ncb2466

[14] NAKAMURA AJ, REDON CE, BONNER WM, SEDELNIKOVA OA Telomere-dependent and telomere-independent origins of endogenous DNA damage in tumor cells. Aging 2009; 1: 212-218.

[15] YU T, MACPHAIL SH, BANATH JP, KLOKOV D, OLIVE PL Endogenous expression of phosphorylated histone H2AX in tumors in relation to DNA double-strand breaks and ge- nomic instability. DNA Repair 2006; 5: 935-946. http://dx.doi. org/10.1016/j.dnarep.2006.05.040

[16] TORUDD J, PROTOPOPOVA M, SARIMOV R, NYGREN J, ERIKSSON S et al. Dose-response for radiation-induced apoptosis, residual 53BP1 foci and DNA-loop relaxation in human lymphocytes. Int J Radiat Biol 2005; 81: 125-138. http://dx.doi.org/10.1080/09553000500077211

[17] NAKAMURA AJ, CHIANG YJ, HATHCOCK KS, HORIKAWA I, SEDELNIKOVA OA et al. Both telomeric and non-telomeric DNA damage are determinants of mammalian cellular senescence. Epigenetics \& chromatin 2008; 1: 6. http:// dx.doi.org/10.1186/1756-8935-1-6

[18] MARTIN OA, IVASHKEVICH A, CHOO S, WOODBINE L, JEGGO PA et al. Statistical analysis of kinetics, distribution and co-localisation of DNA repair foci in irradiated cells: Cell cycle effect and implications for prediction of radiosensitivity. DNA repair 2013; 12: 844-855. http://dx.doi.org/10.1016/j. dnarep.2013.07.002

[19] KLOKOV D, MACPHAIL SM, BANATH JP, BYRNE JP, OLIVE PL Phosphorylated histone $\mathrm{H} 2 \mathrm{AX}$ in relation to cell survival in tumor cells and xenografts exposed to single and fractionated doses of X-rays. Radiother Oncol 2006; 80: 223-229. http://dx.doi.org/10.1016/j.radonc.2006.07.026

[20] YOSHIKAWA T, KASHINO G, ONO K, WATANABE M Phosphorylated $\mathrm{H} 2 \mathrm{AX}$ foci in tumor cells have no correlation with their radiation sensitivities. J Radiat Res (Tokyo) 2009; 50: 151-160. http://dx.doi.org/10.1269/jrr.08109

[21] ZHAO J, GUO Z, ZHANG H, WANG Z, SONG L et al. The potential value of the neutral comet assay and gammaH2AX foci assay in assessing the radiosensitivity of carbon beam in human tumor cell lines. Radiology and Oncology 2013; 47: 247-257. http://dx.doi.org/10.2478/raon-2013-0045

[22] MARTIN NT, NAHAS SA, TUNUGUNTLA R, FIKE F, GATTI RA Assessing ,radiosensitivity ' with kinetic profiles of gamma-H2AX, 53BP1 and BRCA1 foci. Radiother Oncol 2011. http://dx.doi.org/10.1016/j.radonc.2011.05.065

[23] MARKOVA E, SCHULTZ N, BELYAEV IY Kinetics and dose-response of residual 53BP1/gamma-H2AX foci: Colocalization, relationship with DSB repair and clonogenic survival. Int J Radiat Biol 2007; 83: 319-329. http://dx.doi. org/10.1080/09553000601170469

[24] SHIM G, RICOUL M, HEMPEL WM, AZZAM EI, SABATIER L Crosstalk between telomere maintenance and radiation effects: A key player in the process of radiation-induced carcinogenesis. Mutation research. Reviews in mutation research 2014. http://dx.doi.org/10.1016/j.mrrev.2014.01.001 